Journal of Contemporary Eastern Asia, Volume 11, No.2: 13-25

http://dx.doi.org/10.17477/jcea.2012.11.2.013

\title{
Digital Revolution? \\ The increasing impact of Internet on China politics
}

\author{
Gregory Coutaz ${ }^{1}$
}

In the wake of the Arab Spring, the Internet's role in aiding dramatic political transformation has come to the fore. Throughout the Middle East, protestors have employed Facebook, Twitter, Youtube and other popular websites to organize and spread news at home and to the outside world. Chinese authorities have been increasingly nervous about the Arab uprisings, and fear that similar events will inspire unrest in China. The new information and communication technologies make it possible for social movements to initiate novel forms of collective actions. The Internet provides new opportunities for political liberalization. In Chinese society, citizens can now participate in politics uninvited. With each passing day, the online community gets stronger. The digital revolution has the potential for broadening democratic principles and could bring democracy to the collective Chinese mind.

\section{Introduction}

For quite some time, "jasmine" has been a stalwart of Chinese tea and the subject of a celebrated folk song often heard on telephones while on hold with Chinese officials ${ }^{1}$. Now, it is synonymous with revolution, and it is a banned search word on popular search engines, social networking sites, and in chat rooms. Since Tunisian youth anointed their successful "Jasmine Revolution" against Tunisia's dictatorial president, the innocent flower has become a symbol of revolt across the Arab world. The recent protests in Tunisia, Egypt, Libya, Syria, Bahrain, and Yemen have fueled anxiety among the Chinese regime, which is ever alert for social grievances and domestic discontent. The "Jasmine Revolution" has induced Chinese authorities to block any mention of the sweetly scented flower on Internet portals. Ever since Internet use became a notable part of social and political media in the late 1990s, there have been intense debates about the impact of the Internet on politics. In the wake of the Arab Spring, the Internet's role in aiding dramatic political transformations has come to the fore. Throughout the Middle East, protestors have employed Facebook, Twitter, YouTube and other popular websites to organize and spread news at home and to the outside world. Beijing has been increasingly nervous about the Arab uprisings, and fears that similar events, supported through online networking, will inspire unrest

\footnotetext{
${ }^{1}$ International Doctoral Program in Asia-Pacific Studies (IDAS), National Chengchi University (Taiwan).
} 
in China. Mao Zedong once said: "A single spark can set a prairie on fire". Beijing may not control the spark, but it will do whatever it can to prevent the Internet from spreading the fire.

Historically, technology has changed human societies, and it is meaningful and significant to ask how the Internet impacts China's political development today. In this paper, I shall focus my inquiry on the impact of the Internet on Chinese politics from two angles: how Chinese Internet users employ this new technology to participate in politics and how Chinese authorities try to regulate and control the Internet. I intend to use the functionalist approach as the key theoretical perspective of my study. The emergence of new technology as a tool for mass communication seems particularly relevant to political participation. The Internet can be the medium by which democratic change is attained. Indeed, it reshapes the information environment within which citizens operate and make decisions; it also reduces the costs of interacting and finding information. As a result of these benefits, popular and scholarly interest in the political impact of this new technology has grown unabated. Therefore, the first section of this paper will look at the current debate about how the Internet may have a democratizing influence on politics. Many new terms such as "digital democracy" and "cyberdemocracy" have bound Internet use and democracy closely together in the public mind. The second section examines several cases in which online users have challenged and denounced government abuses in China. This section will also analyze the social characteristics of Chinese Internet users. Finally, I will focus on various forms of political control over the Internet. So far, Chinese authorities have succeeded through censorship in blocking the population from using the Internet as an effective political tool. But are there any means by which the "Great Firewall" may be circumvented? Are there some aspects of Internet use that cannot be censored completely? This paper aims to contribute to the study of democracy in China, and provide a deeper understanding of the Internet's political role.

\section{Welcome to e-democracy}

The linkages between advances in information technology and the development of democracy have long interested policy makers and scholars in the social sciences, especially political science, sociology, and media and communication studies ${ }^{2}$. Modernization has increased the availability of a diverse range of specialized news media, for example newspapers, magazines, radio, television, and now the Internet, providing a rich and dense source of information for citizens. This development has produced in Western countries an electorate that is better educated to participate in and more sophisticated about public affairs. Since the coming of the Internet age, technological determinists - who focus on technology as the causal/independent variable - share the belief that the Internet can empower people by expanding their political participation. In the same vein, they argue that information technology can help the transition from authoritarianism to democracy. In other words, they believe that the Internet can promote democracy.

Theories of "digital democracy", "electronic democracy", "cyberdemocracy" or in short e-democracy have been most extensively discussed and used in established Western democracies. They describe the utilization of the Internet and its communication technologies to drive or further democratic processes. Under ideal circumstances, electronic communication technologies can thus enhance democracy in a number of ways. Weare (2002) points out that the Internet contributes to four communication processes that constitute democratic governance. First, the Internet will potentially have profound influences on socialization, a prerequisite for political life. Second, the Internet provides faster and wider channeling which mediates society and the polity and between political actors. Third, through its influence on group dialogue, the Internet will 
significantly alter the role of networks in political life. Fourth, the Internet has the steering potential to control the responsiveness of political systems ${ }^{3}$. According to Weare, the Internet facilitates access to information, encourages political participation, and promotes interactions, which positively and directly affect the structures and organization of Western societies. The last decade has witnessed the Internet as a catalyst for generating growth and economic development. The next decade should establish the democratic potential and capabilities of online communication technologies. Given its open organization and relatively low cost, the proponents of edemocracy call for: "an effort to make the Internet more widely available, involve more people and encourage individuals and communities into the habit of political participation"4. The impact of the Internet is ultimately not the same within democratic or nondemocratic societies. In the latter, the Internet is the empowering force. It has the ability to benefit and empower online users by lowering the barriers to the creation and distribution of a variety of political content throughout repressive regimes. It offers to political activists and other dissident movements anonymity, meaningful connections, and, most of all, a voice. As the traditional means of communication and information may have been co-opted and captured by authoritarian governments, the Internet presents the potential for seizing and re-aligning the cultural and speaking capital.

On the other hand, there are pessimistic views which point out that the effects and developments associated with the Internet are not necessarily positive or robust. For the pessimist camp, the progress in information technology does not mean that there will be improvement in human conditions ${ }^{5}$. Whether the Internet can promote democracy depends more on the political, institutional, and historical context in which the Internet operates. Among others, two concerns have been prominent in the skeptic argumentation. First, the new information technology is widening the existing digital divide, which hinders a real democratic process. Thus, the Internet is not only unable to change inequalities of power and wealth, which are regarded as major barriers to political participation, but it has also unleashed new inequalities that have reinforced deeper divisions between the information rich and the information poor. Several studies, for example, have found continuing correlation between Internet access and income, occupation and education, together with evidence that differentials among the two groups are widening rather than narrowing ${ }^{6}$. The digital divide makes the digitally mediated public sphere exclusive rather than inclusive. Ideally, democratic participation must be inclusive; i.e. everyone should have the possibility to access and use the information technology to express preferences and influence politics. The structuralist critique of the role of the Internet will be analyzed in the following section. Second, information technology has the potential for enhancing social control. Indeed, it is the official authorities that remain the gatekeepers of the boundaries of public information and opinion formation. The Internet provides the infrastructure for the consolidation and expansion of dominance through surveillance and regulation. Skeptics believe that the Internet exerts a negative influence on democracy, and is in fact strengthening governments' power through tight control. In this sense, the monopoly on information empowers the state to encourage certain behaviors and threaten draconian punishments for their violation. It is widely acknowledged that China, for example, is developing some of the world's most sophisticated filtering technologies to control speech and online access for citizens, and is cracking down on various forms of online subversion, imprisoning advocates who have used the Internet for political purposes. The significant impact of Chinese officials on Internet development will be discussed in the last section of this paper.

Both optimistic and pessimistic views offer a broad understanding of the Internet's effects on democracy. The Internet has provided a new political arena where state and society 
compete for power. It is certainly too early to declare who is the winner and who is the loser. The state undoubtedly takes advantage of the new technology information to regulate the system and empower itself, but there are cases in which less organized groups have succeeded in organizing actions to challenge the power and the influence of the state. In these cases, information technology enables those groups to overcome resource limitations and other barriers to gain political power. The encouraging success of the Arab uprisings constitutes an important victory for civil society and the online community. Unfortunately, it is not certain that the recent events in the Middle East will spread to other parts of the world and help citizens overthrow authoritarian regimes.

\section{China and the Internet}

The functionalist approach promotes the potential of the Internet as a democratizing force. But many questions have yet to be answered concerning its real influence on China's political development. I shall turn now my attention to the characteristics of online users and their activities in the Middle Kingdom. Driven primarily by economic incentives, China began its first flirtation with the Internet in May 1994, when it became the $71^{\text {st }}$ country to register with the global computer network. Since then, China has actively embraced the creation and rapid expansion of information technology. In 1995, Chinanet, a new Chinese Internet service provider, was launched as the country's first nationwide network. Today, China has the largest number of Internet users in the world, 420 million (about $32 \%$ of the population) - or roughly the combined population of the United States and Japan. The number of users is steadily growing with more students, intellectuals, professionals, the business community and average urban Chinese getting on to the information superhighway and participating in the transnational flow of information ${ }^{7}$. The infrastructure of the country's digital networks is modern and sophisticated. For example, more than $90 \%$ of Chinese users have broadband access to the Internet because of massive rollouts and competitive prices of digital subscriber line (DSL) networks and almost $20 \%$ of mobile phone users have access to the Internet via their mobile phones ${ }^{8}$. China may have been slow to adopt the new information technology, but it is catching up rapidly. The Chinese equivalents of Facebook or My Space, once niche applications, are becoming social-interaction platforms for hundreds of millions of Chinese. Online social networking is now an integral part of many people's lives and a natural extension of personal communication. The typical Internet user is mainly from the generations born after China launched its one-child-per-family policy in the mid-1970s. These individuals are "looking for friendship and social engagements in cyberspace to compensate for [their] lonely (and sometimes isolated childhood"9. This probably explains the rapid take-off of social online services, including the blogosphere and community-based forums. Indeed, it is estimated that more than half of Chinese Internet users have personal blogs.

The activities taking place on the Internet in China include entertainment, social networking, personal communications, online information, and e-commerce. However, electronic commerce, including e-shopping, e-banking, and e-payments, still lags behind other activities compared to Western societies. This is due to a lack of trust in the security of the virtual world and the general underdevelopment of personal credit systems in China. Many Chinese are skeptical of using their money to buy things they cannot touch. Nevertheless, the Internet remains an important place to search for information. In fact, most users go online to obtain this information ${ }^{10}$. They search for information on products and services, but they especially use the Internet to read news. Gaining information is, thus, one of the highest priorities for the online community. One 
explanation for such infatuation lies in the country's political setting. In a political arrangement in which the government controls the media, the free flow of information is difficult, and readers are not able to access politically sensitive information or news through traditional media such as newspapers and TV channels, which are tightly controlled by the government. Although significant changes have been made in China's media system since the open-door policy, monitoring information in traditional media remains unchanged. Within such a political setting, the Internet provides alternative information and news sources. Online users can gain information that they cannot obtain from state-controlled media or prohibited public access. The existence of alternative sources of information and news is a prerequisite for a free and democratic society.

The Internet provides new sources of interaction and information. Socially, it has broken down the traditional Chinese walls that used to confine Chinese people within certain boundaries. It offers Chinese citizens unprecedented freedom to voice and mobilize their opinions, which was not previously possible in the Middle Kingdom. The scale and speed of these developments is having a serious influence on political liberalization. Compared with the situation before the information age, social groups and political entrepreneurs are now able to initiate collective action and exert pressure on the ruling regime. In bringing this section to a close, I shall use some empirical cases to elaborate on how Internet-based civic engagement has recently affected Chinese public affairs.

\subsection{Milk Scandal}

In September 2008, news of fresh milk and milk formula tainted with melamine from China broke through the censorship barrier and shocked both domestic and international consumers. At least six infants died, and 300,000 children took ill - with 52,000 requiring hospitalization and 10,700 requiring hospitalization for several weeks. Many children were hospitalized with kidney stones, acute kidney failure and other kidney-related problems all caused by drinking the contaminated milk ${ }^{11}$. People throughout the country learned about the scandal not from their government, but through posts on blogs and other sources of online information ${ }^{12}$. Once the story broke, there was mass public outcry. The parents, hugging pictures of their sick or deceased children, captured the public's empathy, and any attempts to bully, bribe, harass or detain them were met with harsh reprimands from ordinary citizens on Internet bulletin boards. Websites, blogs, and chat rooms provided people with a mode to protest the incident and express their outrage. Zhao Lianhai, a former food safety worker and father of a five-year-old son who suffered kidney stones as a result of melamine contamination, started up a website to share information about the symptoms with other victims. Within days, more than 4,000 families had signed up, and soon the online forum was crammed with discussions that evolved from technical questions and answers about medical care to demands for punishment and compensation. It was not long before Zhao Linahai had become the de facto spokesman, organizer, and lobbyist for thousands of parents whose children had fallen ill after drinking milk laced with melamine. In November 2009, he was arrested and charged with the crime of "picking quarrels and provoking trouble"13. He was released on medical parole in December 2010. However, his freedom of movement has been largely restricted to his neighborhood and official harassment continues. His website was shut down by the Chinese authorities but was later moved and re-launched in Japan.

\subsection{Charter 08}


Charter 08 is an online manifesto initially drafted and signed by 303 courageous Chinese intellectuals and human-rights activists calling for peaceful political reform. It was issued on $10 \mathrm{De}-$ cember 2008 to mark the $60^{\text {th }}$ anniversary of the United Nations Declaration of Human Rights. It is inspired by Charter 77, the Czech manifesto that called for democracy in communist Czechoslovakia. Since its release, more than 10,000 people inside and outside China have signed the charter ${ }^{14}$. Charter 08 is divided into three parts: the first looks back at China's recent history, the second outlines the authors' fundamental principles, the third presents a list of suggested reforms. The charter members call for democratic changes and lay out 19 recommendations that include overhauling the constitution so that "the constitution must be the highest law in the land, beyond violation by any individual group or political party"; separation of legislative, judicial, and executive powers; and systematically implementing general elections for public officials ${ }^{15}$. Charter 08 primarily demands a free and democratic country and the end of one-party rule. The Chinese authorities reacted immediately and nervously to censor the charter. Liu Xiaobo, who was the lead signatory, was detained even before the petition was released. He was later sentenced to prison for "inciting the subversion of state power" ${ }^{\text {. }}$. Other signatories were summoned or interrogated by the police. The charter was deleted from the Internet behind China's "Great Firewall". Since then, Liu Xiaobo was awarded the Nobel Peace Prize in 2010. The Internet has become an effective tool for people from all around the world to express their support. To mark the one-year anniversary of Liu's detention, several actions took place on the Internet. For example, the Laogai Research Foundation ran a ten-day Twitter campaign to advocate for Liu's release. After the end of the campaign, letters demanding his freedom were sent to Chinese President $\mathrm{Hu}$ Jintao, the Chinese Embassy in Washington, the Supreme People's Procuratorate of China (the judicial organ responsible for Liu Xiaobo's case), and US President Barack Obama.

\subsection{High-Speed Train Disaster}

Once a source of great pride for the Chinese government, the high-speed rail network has turned into an embarrassment. A collision between two trains on July $23^{\text {rd }}$ close to the coastal city of Wenzhou in Zhejiang province killed 35 people and injured more than $200^{17}$. At first, users of China's Twitter-like service spread appeals for people to donate blood and help look for lost relatives and friends. Then, Chinese bloggers began to question the authorities' handling of the wreckage from the crash. They criticized the apparently quick decision to clean up the crash site. Images of excavators pushing the wreckage into pits circulated widely on the Internet, triggering speculation that the burial was an attempt to cover up evidence. Indeed, leaked propaganda directives ordered journalists not to investigate the causes and footage emerged of bulldozers shoveling dirt over carriages ${ }^{18}$. New online communication technology has proved a powerful amplifier of public skepticism in the country. In this case, it provided real-time, uncensored insights into a disaster that the authorities would doubtless have preferred to be covered by trusted local officials and party members. "We have the right to know the truth!" wrote one blogger, "that's our basic right!"19. The sacking of three top officials at the Shanghai Railway Bureau did little to silence criticism, especially on the Internet, that the government is more concerned with resuming operations on the affected line than with the loss of life. Beijing sees high-speed trains as a matter of national prestige, highlighting China's development, but critics appear to see the disaster as symptomatic of the country's problems. Online users repeatedly described the crash as a man-made accident and blamed officials. "When a country is so corrupt that one lightning strike can cause a train crash (...) none of us is exempt. China today is a train rushing through a light- 
ning storm (...) we are all passengers" ran one of the most frequently forwarded comments on China's Twitter-like service ${ }^{20}$.

The Internet has changed the interaction between the government and the polity in different ways. First, it has undermined the monopoly of information on the part of the communist regime. Individuals are no longer limited to traditional media, but are able to obtain information from alternative news sources. Web sites, search engines, and personal blogs are now used to cover significant social issues ignored by the official media. Second, online technology provides a public space for civic engagement. It plays a considerable role in enabling ordinary Chinese to take part in events as they occur. The Internet has become an effective tool to allow members of society to express their opinions outside the state-controlled press and the state legal system. In other words, it empowers them to participate in public affairs. Popular sentiments rapidly build up and create tremendous pressure for the authorities to act quickly. Third, civic engagement, instead of increasing confidence in politics, has led to public distrust. As blogs, online videos, online forums, and text messaging become popular, they are also used for contention. Social protests constitute an integral part of this new Chinese online activism. Largely spontaneous, they occur in reaction to incidents of public scandal and social injustice.

\subsection{Digital Divide}

Many functions of the Internet demonstrate the potential to facilitate public participation in politics. However, the structuralist approach argues that although information and communication technologies provide a new medium for expression and opposition, their impact and effectiveness as democratizing forces are largely offset by the digital divide. The concept of "digital divide" refers to inequalities between individuals, households, and geographic areas in access to Internet connectivity and in the knowledge and skills needed to use the information gained. But does a digital divide really exist in China today, and does it dampen the Internet's democratic role? As revealed by official statistics from the China Internet Network Information Center (CNNIC), it seems that there is a significant digital divide separating Chinese information "haves" and "have nots". Financial, educational, and geographic factors have restricted people's access to the Internet. Digital inequalities empower some social groups and not others. In a 2002 CNNIC survey, two-thirds of all Internet users in the Middle Kingdom were 30 years old or younger, and almost $80 \%$ were under 35 . Approximately $90 \%$ of Internet users had attained at least a high school degree, and more than $60 \%$ attended college. Users were heavily concentrated in prosperous provinces and municipalities in China's economically dynamic coastal areas around Beijing, Shanghai, Jiangsu, Zhejiang and Guangdong ${ }^{21}$. According to The Survey on Internet Usage and Impact in Five Chinese Cities (Liang \& Wei, 2000), conducted by the Chinese Academy of Social Sciences, the biggest problem remains the financial $\operatorname{cost}^{22}$. Since registration fees and a computer cost as much as a rural villager's annual income, Internet access remains unavailable for large segments of the Chinese population. In addition to economic disparity, lack of access to the knowledge and skills, equipment and software necessary to gain entry to the new information and communication technologies are primary reasons for the digital divide in China. The structuralist critique asserts that unequal access to the Internet makes it problematic for the Internet to become a substitute for more traditional forms of civic engagement.

Although information and communication technologies can help ignite social and economic development, they can also result in the marginalization of developing areas. This marginalization occurs most often when the Internet is haphazardly distributed. The proponents of 
structuralism were right to emphasize the unequal distribution of new technologies in the early 2000s. However, the current situation cannot be compared with that of a decade ago. Over the last ten years, there has been an explosion in the use of the Internet in China. The gap caused by the digital divide is beginning to close. The percentage of the population using the Internet has been increasing dramatically each year. In the year 2000 , only $1.7 \%$ of the population were Internet users. By 2010, that percentage had increased to 32\%. The "Go West" project in the Tenth Five-Year Plan (2001 - 2005) called for the improvement of infrastructure in Western regions of the country. Although it was mainly aimed at improving transportation infrastructure, approximately one million kilometers of new fibre-optic cable were laid alongside the installation of satellite telecommunications facilities between 2001 and $2005^{23}$. According to the latest figures from CNNIC, the number of Internet users in China rose to 420 million by the end of June 2010, an increase of almost 36 million users in the first six months of year 2010, including 115.1 million users in rural areas ${ }^{24}$. From 2008 to 2009, the growth rate of the number of rural Internet users was $26 \%$. Mature net citizens comprise a larger percentage in the age structure of the Chinese Internet users than before, and those above the age of 30 account for $41 \%$ of the total. At the same time, the educational background and income level of Chinese Internet users have dropped. For example, the growth rate of net citizens who have received an education below primary school and junior middle school is now beyond that of overall Internet users ${ }^{25}$. It can hardly be argued that the digital divide has a limiting impact on political participation due to the fact that modern information technology is increasingly becoming affordable for the majority of the population. At the present time, it seems, thus, difficult to maintain the assertion that a digital divide still affects civic engagement.

\section{Internet Control}

While Chinese officials have taken steps to encourage the growth of the country's Internet sector, giving tax breaks to high-tech firms and building low-cost office space for start-ups, they also view the Internet as a serious threat to their authority. China has, thus, the most extensive Internet censorship in the world, more effective even than Saudi Arabia. It is estimated that the Chinese "online police" force of 30,000 to 40,000 members constantly monitors Internet content and usage. This censorship includes, for instance, varied sites such as the New York Times, Washington Post, CNN, Human Rights Watch, and so on. More importantly, Chinese-language sites are also monitored to keep a tab on who is saying what on which site. In December 2002, researchers at the Harvard Law School's Berkman Center for Internet and Society found that of 200,000 websites they tried to access, 50,000 were inaccessible from China on at least one occa$\operatorname{sion}^{26}$. Following the political protests of the "Orange Revolution" in the Ukraine, Beijing updated its regulations controlling online news and information, and aggressively leaned on websites hosting chat rooms and blogs to stop the spread of any form of political opposition. According to the 2005 regulations governing "Internet News Information Service", websites are forbidden from posting content deemed to be "violating the basic principles as they are confirmed in the Constitution" or "jeopardizing the security of the nation, divulging state secrets, subverting the national regime or jeopardizing the integrity of the nation's unity ${ }^{27}$. Information and communication technologies are seen by Chinese officials as a potential Trojan horse introduced by the West to an unwitting Communist China. Since the revolutions in the Arab world, Beijing has been more and more anxious, and fears that similar events, supported through online networking, may inspire unrest in the country. As recently as last September, the Ministry of Public Security 
urged the police to use blogs to "guide public opinion" and "pay attention to hot topics people are talking about on the Internet" 2 . The Chinese government also established a new "State Internet Information Office" to better regulate the flow of online information. As online activism challenges its authority, the state responds by adjusting and refining its institutions and methods of control.

How can the government possibly police millions of weblogs? One way to do it is by forcing domestic - as well as foreign companies (Cisco, Google, Microsoft, Yahoo!) - to integrate censorship into their processes as a precondition of doing business in the Middle Kingdom ${ }^{29}$. Companies that develop such software and technologies are contributing to Internet controls by allowing Chinese censors to block information. Lists of keywords for filtering are often handed out to those companies. In February 2006, the Washington Post obtained one such list from one of the blog-hosting companies. Journalist Philip Pan observed: "Of 236 items on the list, 18 were obscenities. The rest were related to politics or current affairs" ${ }^{\prime 30}$. Major online companies that run forums also hire full-time editors to manage content. Although their main job is to promote forum activity, content editors are also responsible for monitoring illicit information. Some companies are not given a list by the government, but rather are left to their own devices to censor user content to the government's satisfaction. The DoNews service, for example, prevents their users from publishing posts containing politically sensitive phrases such as "Falun Gong", "Tiananmen Square", "Taiwan and Tibet independence" 31 . Their "goal" is achieved when the number of phone calls received from various official departments complaining about the content decreases. By contrast, when the frequency of calls increases, they know that they must tighten controls further in order to avoid trouble. Even Chinese universities are not immune from Internet policing: Shanghai Normal University has gathered 500 student "volunteers" to monitor student discussion groups online ${ }^{32}$. The task of "online police" is to view websites, emails, and forum discussions to make sure that people do not perpetrate any subversive activity.

\subsection{The "Great Firewall"}

As the Internet experiences extraordinary growth in service as well as users, Beijing has undertaken to limit access to any content that might potentially undermine the state's control or social stability by pursuing strict supervision of online content. The "Great Firewall", also known as the Golden Shield Project, is the most notorious example of the government's assertion of sovereignty over the Internet. The "Great Firewall" is a nationwide system of Internet censorship and surveillance operated by the Ministry of Public Security. The project was initiated in 1998 and began operations in November $2003^{33}$. A major part of the project includes the ability to block content by preventing IP addresses from being routed through servers and consists of standard firewalls and proxy servers at the Internet gateways. In fact, the "Great Firewall" prevents certain websites from entering the country. When a computer in China attempts to connect to a website hosted by a country outside China, the request is stopped at the border by a router. If the website is blocked then the information cannot be accessed. This system can be so complex that instead of simply blocking out entire websites, it might only block out parts of the website that contain certain restricted words. For example, the sports section of the BBC can be seen on the Internet in China, but not the news section ${ }^{34}$. This system of control and censorship is considered to be one of the most sophisticated in the world. The implications of the "Great Firewall" are wellknown. The problem, however, is that many of the technologies used in computer security could 
also be employed to restrict human rights and democratic participation through intimidation and systematic surveillance of the population.

A very sophisticated Internet control regime does not mean that the Chinese authorities can always exercise effective surveillance. Internet users in China are very sophisticated, too. The development of new information and communication technologies often enables them to find ways to get around the censors. Three forms may be identified ${ }^{35}$. The first involves technical tools, which basically entails using codes to break other codes. Examples are proxy servers, antiblocking software and, for more savvy online users, rewriting computer programs to disarm firewall filtering functions. Many Internet forums in Chinese cyberspace are full of information and technical advice about how to overcome official censorship mechanisms. The second employs overseas servers, which are not bound by China's rules and regulations, so Chinese Internet users can find international connections to access banned information. They do not hesitate to create dozens of blogs and websites. If one is shut down, they open another, now that the technology makes this easy. For example, a Chinese owner of an anticorruption website created numerous web logs: "I created about 80 blogs. For some time, there were people who tried to block and close my blogs. More than thirty of them were killed one after another. But I still have about fifty of them running" ${ }^{\prime 3}$. The third is linguistic. Firewalls block preassigned values such as the characters for "Tiananmen" or "Falun Gong", but language users are infinitely more creative than computer programs. Through practice, they have developed an entire repertoire of symbolic devices such as character separation, punctuation, homophony, and pictures to cheat the filters. Chinese Internet users are, indeed, skilled social actors. They have developed creative ways of fighting Internet control, and do not fear to engage in "guerilla warfare" with the authorities.

\subsection{From Liberalization to Democratization}

Over the past decade, an Internet-control regime that combines legal, administrative, and technological means to limit online democratization has formed in China. This control regime, however, is torn by the contradictions between the priorities of economic development and ideological surveillance. In addition, popular demands for government transparency, greater accountability, and citizens' rights to be informed act as countercurrents against global control. Progress in information technology has empowered social forces in their interaction with the authorities. Both the state and society can use the Internet in their favor. Interactions between control and resistance have given rise to a type of informational politics. For citizens, the new politics means a field of struggle. In recent years, more and more demands for information access, information disclosure, and the right to knowledge have appeared in China. This new discourse is tied to citizens' use of new information and communication technologies. The current form of activism marks some significant differences from the freedom movements of the past. It differs, for example, from the students' protests of the late 1980s. It happens, thus, more frequently, involves a broader range of issues, has a broader social base, and can be either spontaneous or organized. The main form of online activism includes setting up campaign Web sites, online petitions, mass mailings, posting messages in personal blogs and forums, online broadcast of offline activities, and so on. ${ }^{37}$

The Internet has made it possible for social movements to initiate novel forms of collective action. Online activists are able to overcome resource barriers by using comparatively inexpensive technologies. The new information and communication technologies enable the organizer of a collective action to initiate mobilization to challenge the power and the influence of the 
government. The Internet has definitely provided new opportunities for political liberalization in China. Some particular types of liberalization such as regime openness, transparency, and political accountability would be unlikely without the presence of the Internet. Unfortunately, Internet-based activism has its own limitations. Such collective actions are able to promote political liberalization, but so far they have not been able to trigger political democratization. This is because democratization requires a structural change to the existing regime, but liberalization does not $^{38}$. At the moment such a structural change is apparently not happening in China. Certainly, any regime change will not happen in a clear-cut way. The Internet alone cannot lead to democratization, but together with other developments such as the market economy, globalization, capitalism and class differentiation can be forces that create significant dynamics for political changes in the long run. Compared with the situation before the Internet age, the government feels now more accountable to citizens. Such a change is due to the existence of online activism that enables social forces to exert pressure over the regime. The Internet can be a medium and tool for democratization. But it should not be confused with being a cause of change. The causes will be much broader social, economic and political factors. Given the right circumstances, online activities will positively contribute to facilitate, amplify, and accelerate these causes.

\section{Conclusion}

The Arab Spring in Tunisia, Egypt and elsewhere in the Middle East have relied heavily on new information and communication technologies such as Twitter, Facebook and YouTube. During these movements, the Internet proved to be useful for information dissemination and news gathering, social media for connecting and coordinating groups and individuals, mobiles phones for taking photographs of what was happening and making it available to a worldwide audience. For activist groups, all of these digital tools allow them to bring together remote and often disparate protesters and give them channels to overcome traditional media, which is usually controlled by the government and therefore unwilling to broadcast any news of civil unrest. However, it would be wrong to assume that these revolutions would not have occurred without social media - as many revolutions have occurred in recent times in places with low rates of Internet penetration. The Internet may not bring revolution, but it undoubtedly constitutes an indispensable asset to the liberalization process.

In Chinese society, the Internet has the potential for broadening democratic principles in the authoritarian regime. It provides a new opportunity for citizens to speak up, link up, and act up against daily corruption and increasing inequality. By using online networks, Chinese citizens can participate in Chinese politics uninvited. They practice their own unofficial democracy. Websites, blogs, and forums articulate people's aspirations for basic democratic rights: i.e. the right to voice their opinions on government policies, to be informed of issues that affect their lives, to freely organize themselves and defend their interests, to publicly challenge authorities and social injustice, and to be able to enjoy equal rights and human dignity ${ }^{39}$. It is fair to say that the growth of Chinese cyber society is facing both difficulty and promise. The Internet has yet to achieve its democratic potential to the fullest in the Middle Kingdom. Its effectiveness as a democratic asset remains contingent upon existing socio-economic and political arrangements within Chinese society and on outside influences. When it comes to political change or democratization, the impact of new technologies is more likely to be gradual and subtle. In the long term, as Internet use becomes more and more popular across the country, its impact on politics will be stronger. Online activism will continue to mature, deepen, and develop. Over the course of a genera- 
tion, a new group of citizens - who have grown up using blogs and other forms of online participatory media, debating public affairs and engaging in critical thinking - will emerge. In this short paper, I have tried to address the relationship between the Internet and democracy in China, and demonstrate the effect of the new information and communication technologies on China's political landscape. Western media attention tends to focus too much on cases/examples where online citizens clash with the authorities or the Internet companies who act as proxies for the official censors. These examples are important, but they only constitute a single part of the transformation that is happening, much more quietly, under the surface. Powerful socio-political change is expected as a result of the millions of online activities taking place daily within the Chinese Internet community. With each passing day, the online community grows stronger. The digital revolution is on the move and will participate to free the collective Chinese mind.

\section{Notes}

1 The song was supposedly the favourite of China's previous leader, Jiang Zemin, who asked it to be played at the 1997 transfer of Hong Kong. Videos also exist of President, Hu Jintao, singing the song while on a visit to Kenya.

${ }^{2}$ Yongnian Zheng, Technological Empowerment; The Internet, State, and Society in China, Stanford University (Press: California, 2008), 79.

${ }^{3}$ Christopher Weare, "The Internet and democracy: the causal links between technology and politics", International Journal of Public Administration, Vol. 25 (2002): 659-692.

${ }^{4}$ Maggie Zhang "Click on Democracy: Internet Regulation and Its Implications for Democracy in China" (Paper presented to 54th Annual Conference of International Communication Association, Asian Communication Regulation Division, New Orleans, Louisiana, May 2004).

${ }^{5}$ Zheng, Technological Empowerment, 83.

${ }^{6}$ Zhang, "Click on Democracy".

${ }^{7}$ Sonika Guptka, "The Internet and Democracy in China", The Indu, September 8, 2001.

${ }^{8}$ Marina Y. Zhang and Bruce W. Stening, China 2.0, (John Wiley \& Sons Ltd.: Singapore, 2010).

${ }^{9}$ Ibid., 7.

${ }^{10}$ Percentage of Internet Users Engaging in Various Online Activities: Instant Messsaging (87\%), Online Music (83\%), Reading News (80\%), Online Videos (76\%), Search Engines (69\%), Online Gaming (55\%), e-commerce $(28 \%)$.

Aguiar M., BouTenko V., Michael D., Rastogi V., Subramian A. and Zhou Y., The Internet's New Billion; Digital Consumers in Brazil, Russia, India, China, and Indonesia, (The Boston Consulting Group, September 2010).

${ }^{11} \mathrm{http}: / /$ news.bbc.co.uk/2/hi/7720404.stm

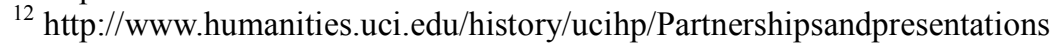
/CCHE\%20unit\%2009.pdf

${ }^{13} \mathrm{http}: / /$ in.reuters.com/article/2009/12/22/idINIndia-44913620091222

${ }^{14}$ An English translation of the charter can be found at this address: http://www.hrichina.org/content/238

${ }^{15}$ Helen Wang, "Liu Xiabo and Charter 08", Forbes, August 10, 2010.

${ }^{16}$ Ibid.

${ }^{17} \mathrm{http}: / /$ www.bbc.co.uk/news/world-asia-pacific-14262276

${ }^{18} \mathrm{http}: / /$ www.economist.com/blogs/banyan/2011/07/chinas-high-speed-train-crash

19 Tania Branigan, "Chinese anger over alleged cover-up of high-speed rail crash", The Guardian, July 25, 2011.

${ }^{20}$ Ibid.

${ }^{21}$ Zhang, "Click on Democracy", 29.

22 Ibid.

${ }^{23}$ Karsten Giese, "Internet growth and the digital divide: implications for spatial development", in China and the Internet. Politics of the Digital Leap Forward, edited by Christopher Hughes and Gudrun Wacker, (Routledge: London, 2003), 46. 
${ }^{24}$ http://www.cnnic.net.cn/uploadfiles/pdf/2010/8/24/93145.pdf

${ }^{25}$ Ibid.

${ }^{26}$ Berkman Center for Internet \& Society at Harvard Law School Research, December 19, 2002. Retrieved from http://cyber.law.harvard.edu/filtering/china

${ }^{27}$ Rebecca McKinnon, "Flatter world and thicker walls? Blogs, censorship and civic discourse in China", Public Choice, Vol. 134 (2008): 37.

${ }^{28}$ Richard Fontaine and Will Rogers, "China's Arab Spring Cyber Lessons", The Diplomat, October 3, 2011. http://the-diplomat.com/2011/10/03/china\%E2\%80\%99s-arab-spring-cyber-lessons

${ }^{29}$ Elijah Dann and Neil Haddow, "Just Doing Business or Doing Just Business: Google, Microsoft, Yahoo! and the Business of Censoring China's Internet”, Journal of Business Ethics, Vol. 79 (2008).

${ }^{30}$ McKinnon, "Flatter world and thicker walls?", 37.

${ }^{31}$ Ibid.

${ }^{32}$ Dann and Neil, "Just Doing Business or Doing Just Business".

${ }^{33} \mathrm{http}: / /$ www-cs-faculty.stanford.edu/ eroberts/cs181/projects/2010-11/FreedomOfInformationChina/the-greatfirewall-of-china-background/index.html

${ }^{34}$ Dann and Neil, "Just Doing Business or Doing Just Business".

${ }^{35}$ Guobin Yang, The Power of the Internet in China, (Columbia University Press: New York, 2009), 60-62.

${ }^{36}$ Ibid, 61.

${ }^{37}$ Ibid., 33.

${ }^{38}$ Zheng, Technological Empowerment, 102.

${ }^{39}$ Yang, The Power of the Internet, 225-226. 